\title{
Case Report: Schwannoma of the sigmoid colon: a case report of a rare colonic neoplasm and review of literature [version 1;
} peer review: 2 approved]

\author{
Gangmi Kim(D1, Sun Il Kim (iD)2, Kang Young Lee1 \\ ${ }^{1}$ Department of Surgery, Severance Hospital, Yonsei University College of Medicine, Seoul, 03722, South Korea \\ ${ }^{2}$ Department of Pathology, Severance Hospital, Yonsei University College of Medicine, Seoul, 03722, South Korea
}

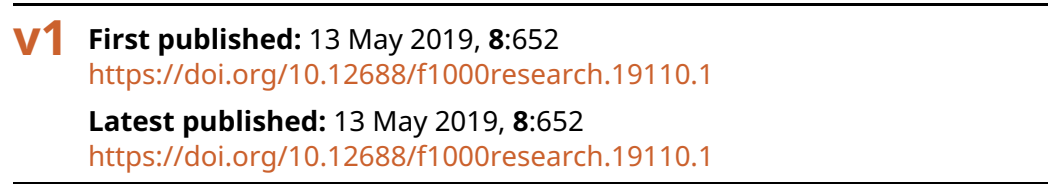

\section{Abstract}

Background: Schwannomas are tumors originating in Schwann cells of the peripheral nerve system and uncommonly develop in the gastrointestinal tract. Sigmoid colon schwannomas are very rare and only 28 cases have been reported. This study aims to report a case of a sigmoid colon schwannoma and present a literature review.

Case report: We report a case of a 66-year-old female with asymptomatic sigmoid colon schwannoma. The patient underwent a screening colonoscopy and about $4 \mathrm{~cm}$ sized submucosal tumor was identified at the sigmoid colon. A colonoscopic biopsy was performed and the microscopic exam revealed an ulcerated lesion with a proliferation of fibroblast-like spindle cells beneath ulcer, which was insufficient for diagnosis. Abdominopelvic computerized tomography (CT) scan showed a well-defined, well-enhancing, round shaped and slightly heterogenous mass at the sigmoid colon. No distant metastasis was identified in abdominopelvic CT and chest CT scans. Carcinoembryonic antigen level was within a normal range $(1.33 \mathrm{ng} / \mathrm{mL})$. The patient underwent laparoscopic anterior resection. Immunohistochemical staining of the resected specimen showed positivity for S-100 protein in tumor cells and schwannoma was diagnosed post-surgically. Surgical resection margins were free from tumor and no regional lymph node metastasis was reported.

Conclusion: Colon schwannomas are rare diseases. Most cases of colon schwannomas are accidentally identified during screening colonoscopy. The tumors usually present as submucosal masses and colonoscopic biopsies are mostly non-diagnostic. Surgical resection is required, and definitive diagnosis is made by confirming S-100 positive tumor cells in immunohistochemical analysis. Most cases are benign; a few cases have been reported to be malignant. Surgical resection with free negative margins is the treatment of choice

Keywords

Colon, schwannoma, colonic neoplasms, colectomy

\section{Open Peer Review \\ Approval Status \\ 1 2 \\ version 1 \\ 13 May 2019

view

view \\ 1. Huaibin Mabel Ko ID, Icahn School of Medicine at Mount Sinai, New York, USA \\ 2. Umut Riza Gunduz ID, University of Health Science, Antalya Training and Research Hospital, Antalya, Turkey}

Any reports and responses or comments on the article can be found at the end of the article. 
Corresponding authors: Gangmi Kim (gangmikim@gmail.com), Kang Young Lee (kylee117@yuhs.ac)

Author roles: Kim G: Conceptualization, Data Curation, Formal Analysis, Investigation, Methodology, Project Administration, Validation, Visualization, Writing - Original Draft Preparation, Writing - Review \& Editing; Kim SI: Resources, Visualization; Lee KY: Resources, Supervision

Competing interests: No competing interests were disclosed.

Grant information: The author(s) declared that no grants were involved in supporting this work.

Copyright: $\odot 2019 \mathrm{Kim} \mathrm{G}$ et al. This is an open access article distributed under the terms of the Creative Commons Attribution License, which permits unrestricted use, distribution, and reproduction in any medium, provided the original work is properly cited.

How to cite this article: Kim G, Kim SI and Lee KY. Case Report: Schwannoma of the sigmoid colon: a case report of a rare colonic neoplasm and review of literature [version 1; peer review: 2 approved] F1000Research 2019, 8:652

https://doi.org/10.12688/f1000research.19110.1

First published: 13 May 2019, 8:652 https://doi.org/10.12688/f1000research.19110.1 


\section{Introduction}

Schwannomas are a common type of tumor of peripheral nerve in adults which originate in Schwann cells. These tumors mainly present along the peripheral nerves and are rarely identified in the gastrointestinal (GI) tract $^{1,2}$. GI tract schwannomas develop most frequently in the stomach (83\%), and less frequently in the small intestine $(12 \%)$, colon and rectum ${ }^{3}$. Sigmoid colon schwannomas are very rare and only 28 cases have been reported so far $^{3,4}$. Most colon schwannomas are incidentally identified as submucosal tumors on screening colonoscopy ${ }^{1,5}$. Colonoscopic biopsies alone usually provides limited information and definite diagnosis is made after surgical resection ${ }^{1}$. Most of the colon schwannomas are benign and surgical resection with adequate free resection margins is the treatment of choice $^{6}$. Here we present a case of sigmoid colon schwannoma and discuss the clinical features of the disease with a literature review.

\section{Case report}

A 66-year-old Asian female patient, who was a housewife, visited a local clinic for a routine screening colonoscopy in mid-January 2018. During the colonoscopy, a submucosal tumor sized about $4 \mathrm{~cm}$ was identified at the sigmoid colon (Figure 1) and biopsy was performed. The microscopic exam of the biopsied specimen showed an ulcerated lesion with a proliferation of fibroblast-like spindle cells beneath the ulcer, which was insufficient for a definite diagnosis.

The patient was referred to our hospital at the end of January 2018. She presented no specific symptom and physical examination showed no specific finding. She had a history of hypertension and a benign breast mass. She had a positive family history of cancer: her father had gastric cancer, and her uncle had lung cancer.

An abdominopelvic computerized tomography (CT) scan revealed $4.4 \mathrm{~cm}$ sized well-circumscribed, well-enhanced, roundshaped mass in the sigmoid colon, which was slightly heterogenous inside. No intraabdominal metastasis was identified

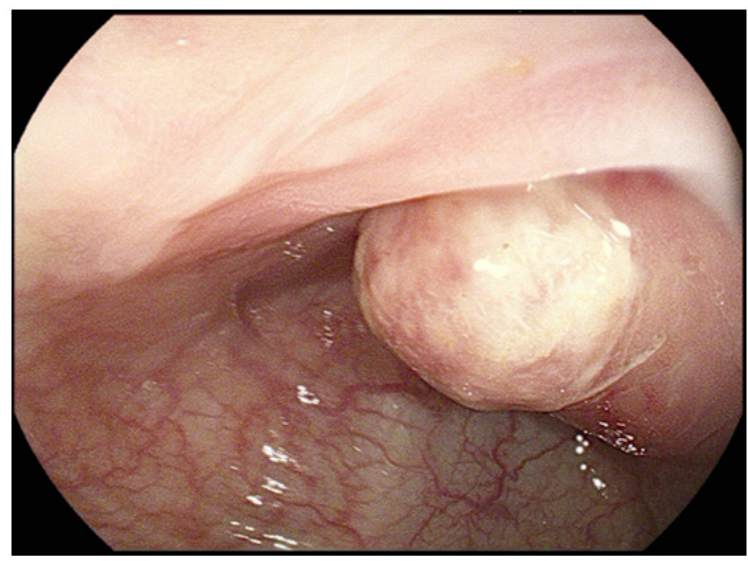

Figure 1. Colonoscopy. About $4 \mathrm{~cm}$ sized submucosal tumor was identified at the sigmoid colon.
(Figure 2A-2B). Chest CT scan showed no intrathoracic metastasis. Carcinoembryonic antigen (CEA) level was $1.33 \mathrm{ng} / \mathrm{mL}$, which was within a normal range $(0.0-5.0 \mathrm{ng} / \mathrm{mL})$. Other laboratory test results were also within normal ranges. Differential diagnosis was 1) gastrointestinal stromal tumor (GIST); and 2) neuroendocrine tumor (NET).

The patient underwent a laparoscopic anterior resection. On laparoscopic exploration, an extruding mass was identified at the anterior wall of the sigmoid colon and no metastasis was observed. The sigmoid colon was mobilized and the inferior mesenteric artery was low ligated. Sigmoid colon resection with end-to-end anastomosis was performed.

On examining the resected specimen, about $4.5 \times 4.0 \mathrm{~cm}$ sized round mass was observed on the surface of the serosa and there was no tumor infiltration to the serosa (Figure 3A-3B). The tumor was located $7 \mathrm{~cm}$ from the proximal resection margin and $4 \mathrm{~cm}$ from the distal resection margin. On sections after fixation, the cut surface showed a yellowish mass $(4.2 \times 3.2 \mathrm{~cm})$, which was abutting on the circumferential resection margin. The mass was relatively well-demarcated without encapsulation (Figure 4). On hematoxylin and eosin (H\&E) stain, the tumor was composed of spindle cells with low nuclear atypia, with nuclear palisading growth pattern, and lymphoid cuffing surrounding tumor cells were identified (Figure 5A-5C). Mitosis was rarely observed (1/50 in high-power field). The remaining mucosa and serosa were grossly unremarkable. The resection margins were free from tumor. Lymph node metastasis was zero in 13 regional lymph nodes. On immunohistochemical analysis, s-100 was strongly positive in tumor cells; otherwise, c-kit, CD34, and SMA were negative (Figure 6A-6D). Finally, the diagnosis was a benign schwannoma of the sigmoid colon.

The patient recovered from surgery uneventfully and was discharged on postoperative day 5 . When she visited the outpatient clinic two weeks after discharge, she did not present any complication. No postoperative adjuvant therapy was performed.

\section{Discussion}

Schwannomas are peripheral nerve sheath tumors which rarely develop in GI tract ${ }^{1,2}$. GI tract schwannomas represent about $2-6 \%$ of all mesenchymal tumors ${ }^{2,3}$.

For the first time, Daimaru et al. clarified the entity of the nerve sheath tumors developing in the GI tract and proposed these tumors to be designated as "benign schwannoma of the GI tract" in $1988^{7}$. Lymphoid cuffing, benign nuclear atypia and positive immunostaining for S-100 protein were the distinct features of the schwannoma of the GI tract, which distinguish the schwannoma from other spindle-cell stromal tumors of smooth muscle origin ${ }^{7}$. Until the early 1990s, most GISTs traditionally had been classified as smooth muscle tumors ${ }^{8}$. Ueyama et al. suggested that most of the GIST had smooth muscle differentiation and excluded schwannomas from the GIST ${ }^{8}$.

Currently, GI tract schwannomas are classified as non-epithelial tumors of which disease entity is clearly distinct from leiomyomas, 

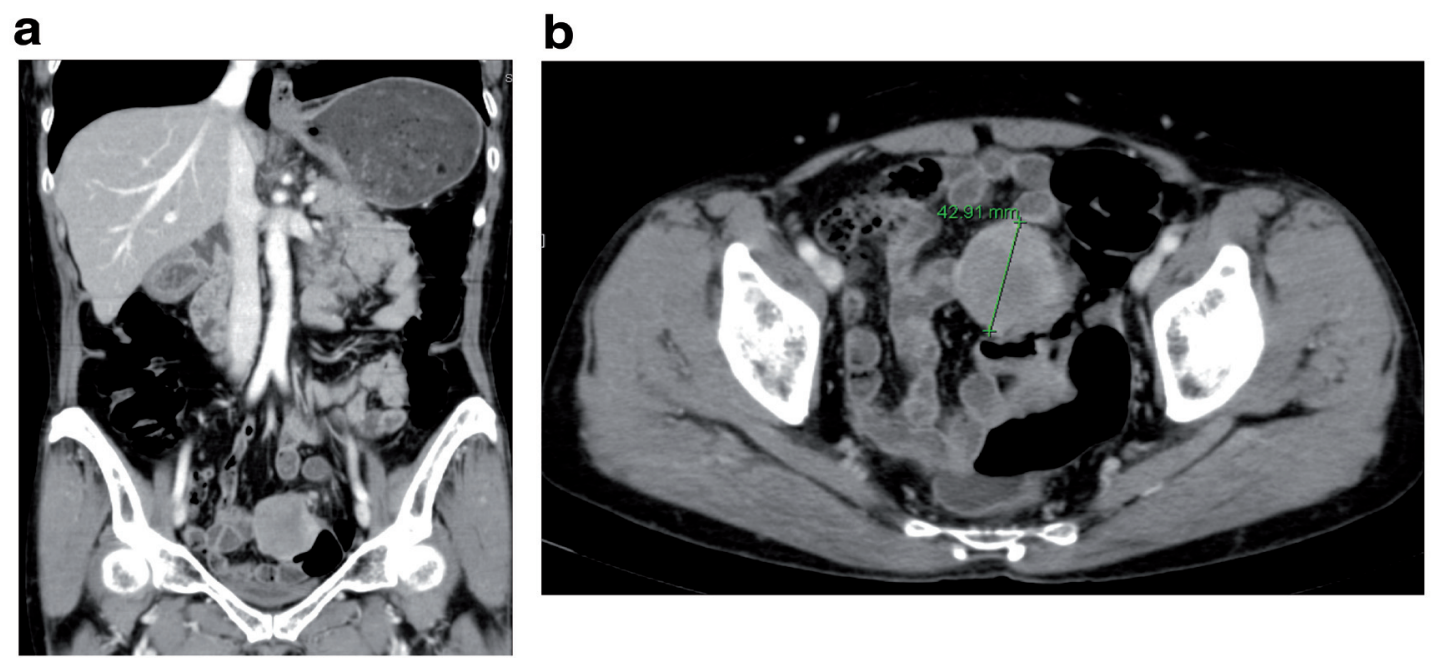

Figure 2. Abdominopelvic computerized tomography (CT). A well-circumscribed, well-enhanced, round-shaped mass was identified at the sigmoid colon. (A) Coronal view. (B) Axial view.
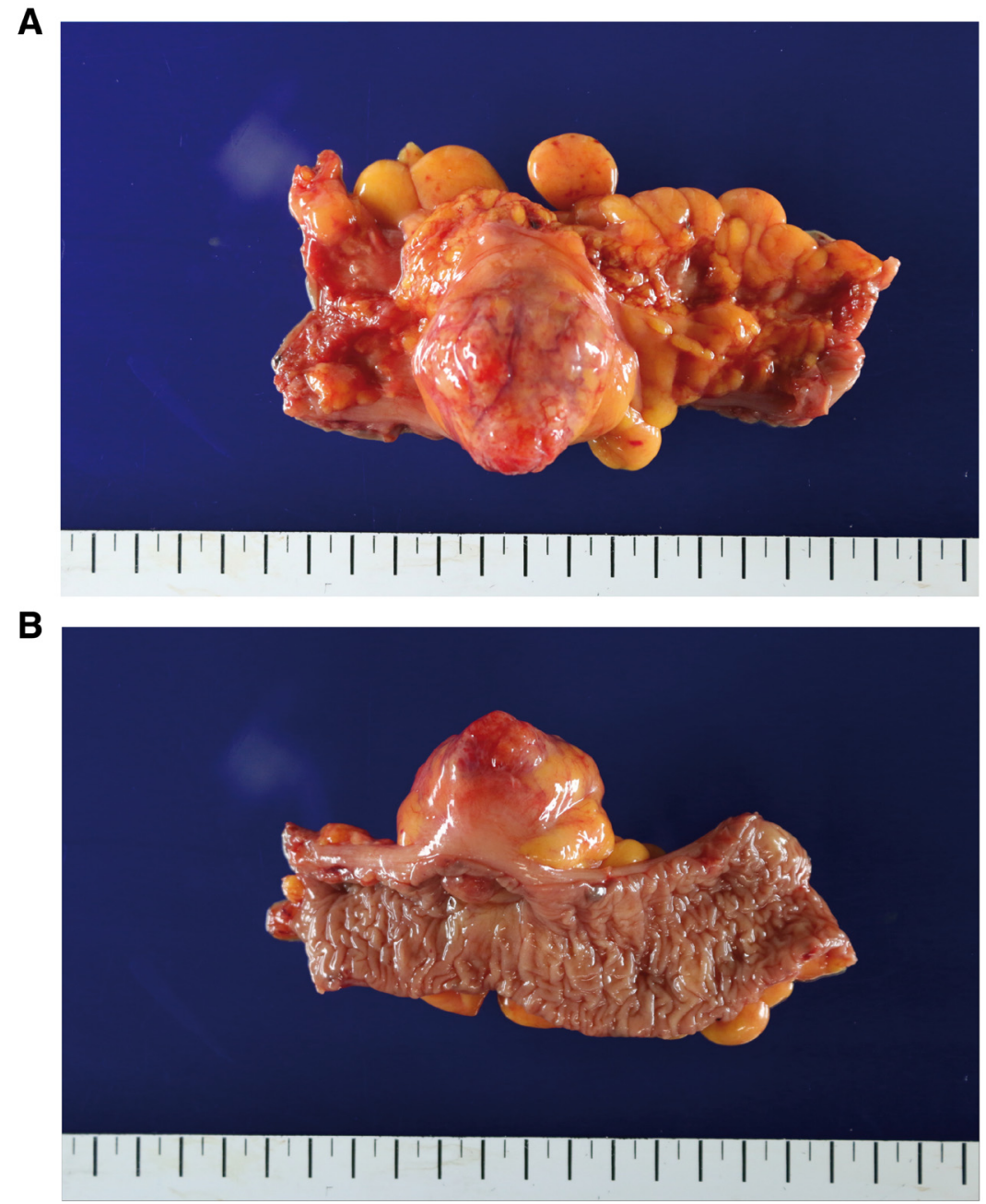

Figure 3. Gross findings of the resected specimen. (A) $4.5 \times 4.0 \mathrm{~cm}$ sized round, protruding mass was observed on the surface of the serosa. (B) The photo was taken from the mucosal side. 


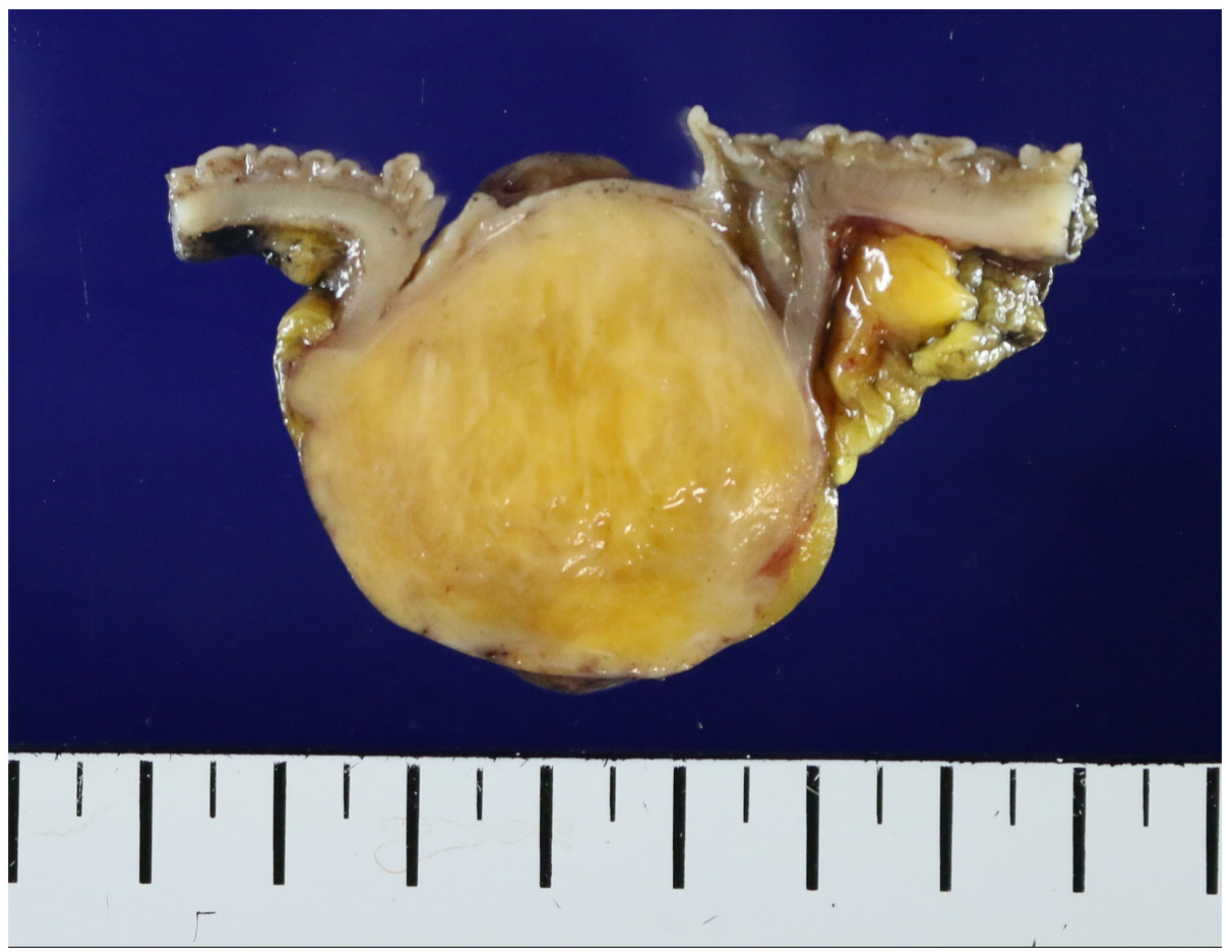

Figure 4. Cut section after fixation. Relatively well-demarcated yellowish mass without encapsulation is shown.

\section{a}

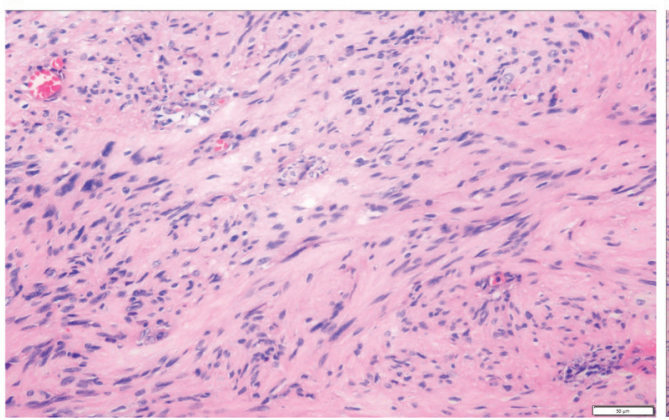

b

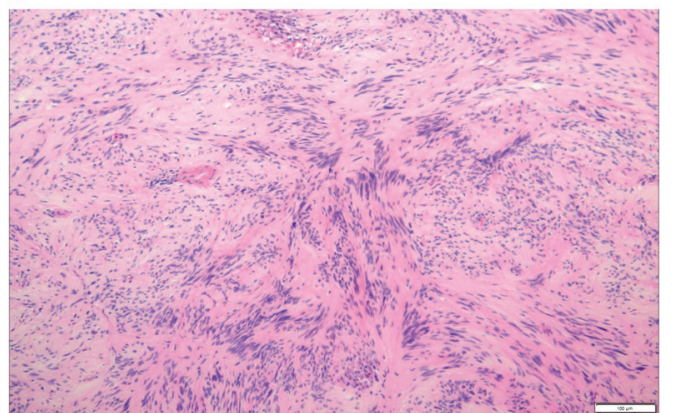

c

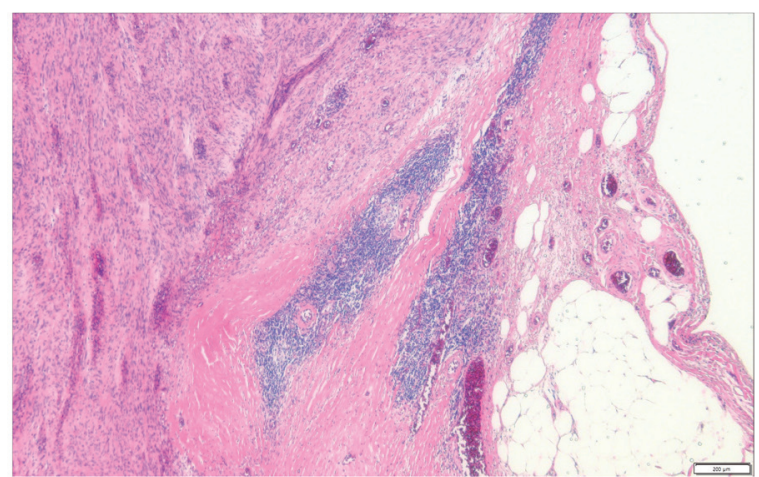

Figure 5. Hematoxylin and eosin (H\&E) stain. (A) The tumor cells are composed of spindle cells with low nuclear atypia. (B) Nuclear palisading growth pattern is shown. (C) Lymphoid cuffing surrounding tumor cells is shown. 
a

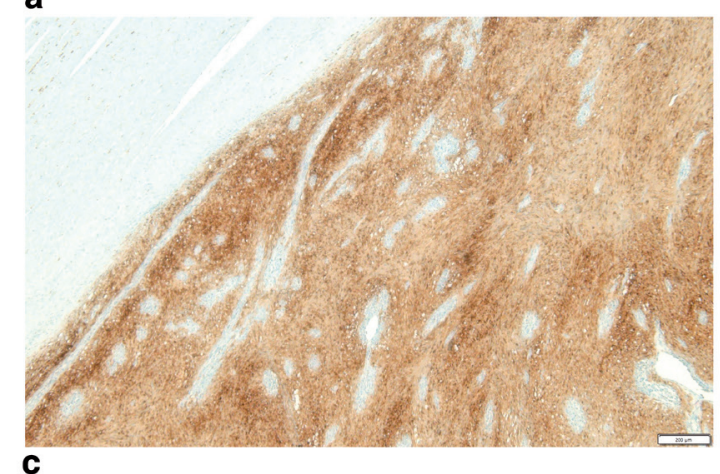

b



d



Figure 6. Immunohistochemical stain. (A) S-100 is diffuse, strong positive in tumor cells. (B) C-KIT is negative in tumor cells. (C) CD34 is negative in tumor cell, but normal vessel structures were stained. (D) SMA is negative in tumor cells, but normal smooth muscle in the proper muscle layer is stained.

leiomyosarcomas, gastrointestinal autonomic nerve tumors (GANTs) and GISTs 2, . And GI schwannomas are considered distinguished from conventional soft-tissue schwannomas and CNS schwannomas².

GI schwannomas are mostly identified in the stomach and less frequently seen in colon, rectum, small intestine or esophagus ${ }^{2,3}$. They are most frequently diagnosed among people in their sixties and the incidence rates are identical for males and females $^{3,9,10}$. Most of them are incidentally identified during screening endoscopy or imaging studies because they are usually asymptomatic. However, just like any other GI tumors, they can present some clinical symptoms such as abdominal pain, tenesmus, rectal bleeding or melena ${ }^{1}$. Sometimes these tumors manifest as colonic obstruction or intussusception ${ }^{4,9,10}$.

Endoscopically, these tumors usually present as a submucosal tumor with smooth mucosa or with mucosal ulceration ${ }^{1-3}$. On CT scans, the tumors usually present as exophytic masses with homogeneous enhancement and cystic change, necrosis, or calcification within tumors are uncommon ${ }^{2}$.

A preoperative diagnosis is challenging because endoscopic mucosal biopsy usually provides limited information to differentiate them from other mesenchymal tumors of GI tract such as GISTs, NETs, leiomyomas, or leiomyosarcomas ${ }^{3}$. In Inagawa's study, only $15 \%$ of the colon schwannomas were diagnosed on preoperative endoscopic biopsy ${ }^{11}$; in Bohlok's study, $24 \%$ of the colorectal schwannomas were diagnosed preoperatively ${ }^{3}$.

Diagnosis is confirmed pathologically with immunohistochemical analysis. Histopathological features of schwannomas are mainly elongated bipolar spindle cells with variable cellularity and sometimes peripheral cuff-like lymphocyte infiltration is exhibited around the tumor, which helps to differentiate schwannomas from other spindle-cell tumors like fibromas or leiomyomas ${ }^{5,7,11}$. Schwannomas can be distinguished from other smooth-muscle tumors by strong s-100 positivity in immunohistochemical analysis ${ }^{11-13}$. Additionally, CD34 or c-kit protein is useful to distinguish the schwannomas from GISTs ${ }^{11-13}$. Schwannomas are S-100 positive, but CD-34 and c-kit negative; most GISTs are s-100 negative, but CD-34 and c-kit positive.

Prognosis is generally promising because most of the GI schwannomas are benign and malignant potential is low ${ }^{1-3}$. However, even though many researchers reported the benign features of GI schwannoma, some of these tumors present local recurrence or distant metastasis. In Bohlok's study, 3 (3.1\%) out of 93 cases of colorectal schwannomas were malignant ${ }^{3}$. High mitosis rate, high Ki-67 index, and large tumor size are considered to be associated with malignancy ${ }^{3}$.

Complete surgical resection obtaining free resection margins is the best therapeutic option ${ }^{1,3}$, because tumor recurrence is 
generally owing to incomplete surgical resection with inadequate margins ${ }^{2}$. In some limited cases, patients can be treated by endoscopic resection or transanal resection without undergoing radical surgery ${ }^{3}$.

Adjuvant therapies are not commonly recommended if surgical resection achieving free margins is completed ${ }^{5,14}$. Currently, limitation of our knowledge is that there is no consensus for subsequent treatment after surgical resection in case of malignant transformation ${ }^{5}$.

Sigmoid colon schwannomas are very rare colonic neoplasms. To our knowledge, only 28 cases of sigmoid colon schwannomas have been published. Because of its rarity and challenge to diagnosis, review of the clinical features of the disease with a presenting case would be of help for physicians and surgeons. We believe that our study presents the clinical manifestations including endoscopic, imaging, histopathologic and immunohistologic findings of this rare disease with a thorough literature review and it provides guidance in diagnosis and treatment of the disease. Limitation of this study is that the treatment strategy for metastatic diseases was not suggested because only very limited cases were reported and no consensus exists for now.

\section{Conclusion}

Sigmoid colon schwannomas are usually found incidentally during screening colonoscopy and present as submucosal tumors.
Preoperative diagnosis is challenging because clinical manifestations, as well as colonoscopic and CT findings, are nonspecific. No specific tumor marker exists either. Histopathologically, the tumors consist of spindle cells. However, colonoscopic biopsies have limitations in terms of a definite diagnosis and differential diagnosis includes schwannoma, GIST, NET, leiomyoma, leiomyosarcoma, etc. Conclusive diagnosis can be made by confirming s-100 proteins in immunohistochemical analysis and mostly confirmed post-surgically. Complete surgical resections with adequate free margins are required because although the majority of the diseases are benign, some are reported to be malignant. There is no consensus for adjuvant chemotherapy.

\section{Data availability}

Underlying data

All data underlying the results are available as part of the article and no additional source data are required.

\section{Consent}

Written informed consent for publication of their clinical details and clinical images was obtained from the patient.

Grant information

The author(s) declared that no grants were involved in supporting this work.
1. Baig MMAS, Patel R, Kazem MA, et al:: Schwannoma in the ascending colon, a rare finding on surveillance colonoscopy. J Surg Case Rep. 2019; 2019(2): rjz046.

PubMed Abstract | Publisher Full Text | Free Full Text

2. Mekras A, Krenn V, Perrakis A, et al:: Gastrointestinal schwannomas: a rare but important differential diagnosis of mesenchymal tumors of gastrointestinal tract. BMC Surg. 2018; 18(1): 47.

PubMed Abstract | Publisher Full Text | Free Full Text

3. Bohlok A, El Khoury M, Bormans A, et al: Schwannoma of the colon and rectum: a systematic literature review. World J Surg Oncol. 2018; 16(1): 125 PubMed Abstract | Publisher Full Text | Free Full Text

4. González Ruiz Y, Reyes Delgado A, Guiterrez Alonso C, et al.: [Sigmoid intussusception as a clinical presentation of colonic schwannoma: Pediatric case]. Arch Argent Pediatr. 2019; 117(1): e68-e71. PubMed Abstract | Publisher Full Text

5. Uhr A, Singh AP, Munoz J, et al.: Colonic Schwannoma: A Case Study and Literature Review of a Rare Entity and Diagnostic Dilemma. Am Surg. 2016; 82(12): 1183-86. PubMed Abstract

6. Çakır T, Aslaner A, Yaz M, et al: Schwannoma of the sigmoid colon. BMJ Case Rep. 2015; 2015: pii: bcr2014208934. PubMed Abstract | Publisher Full Text | Free Full Text

7. Daimaru $\mathrm{Y}, \mathrm{Kido} \mathrm{H}$, Hashimoto $\mathrm{H}$, et al.: Benign schwannoma of the gastrointestinal tract: a clinicopathologic and immunohistochemical study. Hum Pathol. 1988; 19(3): 257-64.

PubMed Abstract | Publisher Full Text
8. Ueyama T, Guo KJ, Hashimoto H, et al:: A clinicopathologic and immunohistochemical study of gastrointestinal stromal tumors. Cancer. 1992, 69(4): 947-55.

PubMed Abstract | Publisher Full Text

9. Wilde BK, Senger JL, Kanthan R: Gastrointestinal schwannoma: an unusual colonic lesion mimicking adenocarcinoma. Can J Gastroenterol. 2010; 24(4): 233-36.

PubMed Abstract | Publisher Full Text | Free Full Text

10. Wang WB, Chen WB, Lin JJ, et al:: Schwannoma of the colon: A case report and review of the literature. Oncol Lett. 2016; 11(4): 2580-82. PubMed Abstract | Publisher Full Text | Free Full Text

11. Inagawa S, Hori M, Shimazaki J, et al:: Solitary schwannoma of the colon: report of two cases. Surg Today. 2001; 31(9): 833-38. PubMed Abstract | Publisher Full Text

12. Miettinen M, Virolainen M, Maarit-Sarlomo-Rikala: Gastrointestinal stromal tumors--value of CD34 antigen in their identification and separation from true leiomyomas and schwannomas. Am J Surg Pathol. 1995; 19(2): 207-16. PubMed Abstract | Publisher Full Text

13. Ramai D, Lai J, Changela $\mathrm{K}$, et al: Transverse colon schwannoma treated by endoscopic mucosal resection: A case report. Mol Clin Oncol. 2017; 7(5): 830-32.

PubMed Abstract | Publisher Full Text | Free Full Text

14. Turaihi $\mathrm{H}$, Assam JH, Sorrell M: Ascending Colon Schwannoma an Unusual Cause of Acute Lower Gastrointestinal Bleeding. S D Med. 2017; 70(1): 33-37. PubMed Abstract 


\section{Open Peer Review}

\section{Current Peer Review Status:}

\section{Version 1}

Reviewer Report 02 October 2019

https://doi.org/10.5256/f1000research.20942.r54272

(C) 2019 Gunduz U. This is an open access peer review report distributed under the terms of the Creative Commons Attribution License, which permits unrestricted use, distribution, and reproduction in any medium, provided the original work is properly cited.

\section{Umut Riza Gunduz}

Department of General Surgery, University of Health Science, Antalya Training and Research Hospital, Antalya, Turkey

The authors presented a case report and a review of related literature about sigmoid colon schwannomas. This is a rare disease and an interesting subject.

Although it is a beautifully written review in general, some corrections are required:

The authors claimed segmenter resection is enough for sigmoid colon schwannoma but in their case report they prefer to anterior resection. it is necessary to explain this in the discussion section.

The authors shared a photo of the specimen they resected in figure 3. This image resembles segmental resection rather than anterior resection.

Is the background of the case's history and progression described in sufficient detail? Yes

Are enough details provided of any physical examination and diagnostic tests, treatment given and outcomes?

Yes

Is sufficient discussion included of the importance of the findings and their relevance to future understanding of disease processes, diagnosis or treatment?

Yes

Is the case presented with sufficient detail to be useful for other practitioners? Yes

Competing Interests: No competing interests were disclosed. 
Reviewer Expertise: Breast cancer, thyroid cancer, endoscopy, ERCP

I confirm that I have read this submission and believe that I have an appropriate level of expertise to confirm that it is of an acceptable scientific standard.

Reviewer Report 31 May 2019

https://doi.org/10.5256/f1000research.20942.r48558

(C) $2019 \mathrm{Ko} \mathrm{H.} \mathrm{This} \mathrm{is} \mathrm{an} \mathrm{open} \mathrm{access} \mathrm{peer} \mathrm{review} \mathrm{report} \mathrm{distributed} \mathrm{under} \mathrm{the} \mathrm{terms} \mathrm{of} \mathrm{the} \mathrm{Creative} \mathrm{Commons}$ Attribution License, which permits unrestricted use, distribution, and reproduction in any medium, provided the original work is properly cited.

\section{Huaibin Mabel Ko}

Division of Gastroenterology, Department of Medicine, Icahn School of Medicine at Mount Sinai, New York, NY, USA

Overall this is a good case report and review of a rare tumor. There are a few small grammatical errors, but the paper is otherwise well organized and easy to follow.

\section{Minor suggestions:}

1. When referring to the size of the tumor, especially when giving dimensions that seem fairly exact ("4.5 x $4.0 \mathrm{~cm}$ ") it is unnecessary to say "about", you can just state the size.

2. Replace "Most of the" with "Most", as in "Most GI tract schwannomas" or "Most colon schwannomas"

3. Figure 6: "proper muscle layer" should be "muscularis propria layer"

Is the background of the case's history and progression described in sufficient detail? Yes

Are enough details provided of any physical examination and diagnostic tests, treatment given and outcomes?

Yes

Is sufficient discussion included of the importance of the findings and their relevance to future understanding of disease processes, diagnosis or treatment?

Yes

Is the case presented with sufficient detail to be useful for other practitioners? Yes

Competing Interests: No competing interests were disclosed.

Reviewer Expertise: Gastrointestinal Pathology 
I confirm that I have read this submission and believe that I have an appropriate level of expertise to confirm that it is of an acceptable scientific standard.

The benefits of publishing with F1000Research:

- Your article is published within days, with no editorial bias

- You can publish traditional articles, null/negative results, case reports, data notes and more

- The peer review process is transparent and collaborative

- Your article is indexed in PubMed after passing peer review

- Dedicated customer support at every stage

For pre-submission enquiries, contact research@f1000.com 